
Informations

une revue Gallia

Lorraine | 2001

\title{
Metz
}

Hôpital Sainte-Blandine, 8 rue d'Asfeld

\section{Pierre Thion}

\section{(2) OpenEdition \\ 1 Journals}

Édition électronique

URL : http://journals.openedition.org/adlfi/8603

ISSN : 2114-0502

Éditeur

Ministère de la culture

Référence électronique

Pierre Thion, « Metz », ADLFI. Archéologie de la France - Informations [En ligne], Lorraine, mis en ligne le 01 mars 2001, consulté le 20 avril 2019. URL : http://journals.openedition.org/adlfi/8603

Ce document a été généré automatiquement le 20 avril 2019.

(c) Ministère de la Culture et de la Communication, CNRS 


\section{Metz}

Hôpital Sainte-Blandine, 8 rue d'Asfeld

\section{Pierre Thion}

\section{Identifiant de l'opération archéologique : F1357200100084}

Date de l'opération : 2001 (EV)

1 La création au sein de l'Hôpital Sainte-Blandine, 8 rue d'Asfeld, d'un bâtiment neuf (bâtiment E) comportant $530 \mathrm{~m}^{2}$ de sous-sol a motivé la réalisation d'un sondage de diagnostic. Ce projet est en effet situé pour l'essentiel dans l'emprise du fossé défensif de la ville et les terrassements nécessaires à sa réalisation étaient notamment susceptibles de rencontrer ponctuellement au sud-est les vestiges d'un éventuel mur de contrescarpe et du terre-plein attenant.

2 Le sondage, poursuivi jusqu'à $-3,80 \mathrm{~m}$, a rencontré à partir de $-2,70 \mathrm{~m}$ un remplissage caractéristique, constitué de remblais grisâtres, l'eau étant présente vers - 3,50 m. Un tesson de grès glaçuré post-médiéval a été recueilli. La berge n'a en revanche pas été reconnue. En l'absence de vestiges structurés ou de niveaux détritiques à la profondeur visée, ce projet n'a pas nécessité d'intervention complémentaire.

\section{INDEX}

Index géographique : Lorraine, Moselle (57), Metz

Thèmes : céramique moderne, fossé, mur

operation Fouille d'évaluation (EV) 


\section{AUTEURS}

\section{PIERRE THION}

SDA 